\title{
TRADUCIENDO A JOSEPH ADDISON: PROBLEMAS Y DESAFÍOS
}

Javier Martín Párraga

Universidad de Córdoba

\section{ABSTRACT}

This paper studies the many problems that arise when translating the essays one of the key figures withing XVIII century England and one of the parents of modern journalism, Joseph Addison. In order to achieve this goal, I will focus my critical interest on an essay published by the autor on March, 8, 1711.

KEY WORDS: Translation, Joseph Addison, English Restoration, The Spectator.

\section{RESUMEN}

El presente artículo analiza los problemas que implica traducir los textos periodísticos de opinión de Joseph Addison, figura clave de las letras inglesas del siglo XVIII y uno de los padres del periodismo moderno. Para llevar a cabo este objetivo, nos centraremos en un artículo publicado en The Spectator el día 8 de marzo de 1711.

PALABRAS CLAVE: Traducción, Joseph Addison, Restauración inglesa, The Spectator.

FECHA DE RECEPCIÓN: 03/11/2014

FECHA DE ACEPTACIÓN: 25/03/2015

PÁGINAS: $35-47$ 
1. JOSEPH ADDISON Y THE SPECTATOR

Joseph Addison (1672-1719) es una de las figuras clave en la cultura inglesa del siglo XVII y comienzos del XVIII, un período histórico caracterizado tanto por las tensiones políticas como por el esplendor de las ciencias en el Reino Unido. Los orígenes de Addison son modestos, pero el entorno familiar fomentó siempre la cultura y educación del autor; ya que su padre, Lancelot Addison, se licenció en el prestigioso Queen's College de Oxford y, además de ejercer las labores de Deán de la Catedral de Lichfield fue un investigador entregado y brillante de cuya pluma salieron no sólo magistrales discursos sino también varios libros.

El joven Joseph Addison cursó sus primeros estudios en la prestigiosa Charterhouse School. Durante esta temprana etapa educativa, nuestro autor entrará en contacto con las que están destinadas a convertirse en las dos de las influencias más permanentes y fructíferas de su vida. En primer lugar, descubre los clásicos, que no dejarán de apasionarle y servirle de inspiración en años venideros. Pero si la educación greco-latina permitirá a Addison desarrollarse como persona y escritor, no lo hará en menor medida otro contacto que hizo en Charterhouse School. En este caso se trata de un joven alumno de su edad con el que compartirá incontables horas de juego y charla y que con el transcurrir de los años se convertirá en su socio editorial: Richard Steele (con el que publicará The Spectator, del que hablaremos más adelante).

Para continuar su educación superior, Addison cursará estudios de Lenguas Clásicas en Queen's College de Oxford, en la que como su padre había hecho antes, destacará como un alumno brillante. Sus vastos conocimientos y facilidad para la compleja tarea de versificar en latín le ganarán a Addison el reconocimiento universitario, que se materializa con la concesión del puesto de fellow en el Magdalen College, de la propia Oxford. Durante estos años, a pesar de su juventud, Addison comienza a ser asimismo conocido y respetado entre los círculos poéticos y académicos de Londres; a raíz de un poema en latín que dedica a John Dryden en el año 1693, de la publicación de su primer libro (una biografía de los poetas ingleses) y de la aparición de su brillante traducción de las Geórgicas de Virgilio, en 1694.

Estas tempranas muestras de talento hicieron que el propio Dryden, junto con Lord Somersy Charles Montagu (Primer Duque de Halifax) consiguieran una asignación de 300 Libras anuales, que permitirían a Addison viajar por Europa mientras seguía consolidando su carrera literaria y se formaba como diplomático. Sin embargo, como decíamos anteriormente, son años convulsos para la política inglesa y en 1702 , con la muerte del soberano Guillermo III, los valedores de Addison pierden sus empleos públicos y contactos políticos y el joven escritor se ve privado de su asignación. 
Privado de fondos, Addison debe regresar a Inglaterra en el año 1703, donde permanece sin empleo ni opciones profesionales durante un año, hasta que en 1704 Sidney Godolphin, Lord Treasurer, le encomienda la redacción de un poema conmemorativo de la batalla de Blenheim. El texto resultante, "The Campaign" satisface hasta tal punto a su influyente empleador que Addison es nombrado Commissioner of Appeals en Halifax. A partir de ese momento, la carrera política de Addison se desarrolla sin mayores contratiempos hasta que en el año 1709 entra en el Parlamento de Irlanda como miembro de la Cámara de los Comunes, hasta 1713 y como representante del condado de Malmesbury; desde 1710 hasta su muerte en 1719.

A lo largo de su carrera política Addison, firme defensor de los ideales whigs se muestra liberal al mismo tiempo que insiste en la necesidad de fortalecer el Reino Unido gracias a una política económica sólida, tanto en el ámbito nacional como internacional. Además de granjear un lugar en la sociedad británica y del prestigio que estos cargos le otorgaron, le permitieron al autor viajar con frecuencia por toda Europa y dedicarse a sus actividades literarias sin presiones financieras, lo que le concedió unas grandes dosis de libertad.

Como autor literario, Addison produjo diversas obras poéticas y tres dramáticas: el libreto para la ópera de Thomas Clayton Rosamond (que se estrenó sin éxito en Londres en el año 1710), la tragedia Cato (que consiguió una excelente recepción crítica en 1712 y puede considerarse como su mejor obra literaria) y, por último, la comedia The Drummer, que se estrena en 1716. A pesar de que su poesía resulta sin duda interesante y de que su corpus teatral merece elogios y estudio crítico, no cabe duda de que el papel de Joseph Addison en las letras inglesa queda asegurado por su labor como articulista y editor de periódicos.

En el año 1709 su amigo de la infancia Richard Steele lanza el periódico The Tattler y durante tres años la publicación sale de imprenta con una periodicidad de tres veces a la semana, con artículos de importantes intelectuales de la época; aunque sin duda eran los propios Steele y Addison, junto con el novelista irlandés Jonathan Swift las mejores y más populares plumas del medio. En 1712, tan sólo dos meses después del cese de actividades de The Tattler, Steele y Addison se asocian de nuevo para editar y publicar The Spectator. Esta nueva publicación, que lanza con la intención de "to enliven morality with wit, and to temper wit with morality" (número 10), aparecerá de manera diaria entre 1711 y 1712 y reaparecerá durante seis meses más (aunque con una periodicidad de tres veces a la semana) en 1714, aunque ya sin la participación de Steele. La tirada diaria del periódico no superaba los 3000 ejemplares, aunque el número de lectores podía muy bien ser veinte veces mayor y la importancia de sus textos para la sociedad y cultural británica son 
Traduciendo a Joseph Addison: problemas y desafíos

tales que Habermas considera que resultan fundamentales para la creación y consolidación de la nueva burguesía inglesa del siglo XVIII:

Addison viewed himself as a censor of manners and morals; his essays concerned charities and schools for the por, the improvement of education, pleas for civilized forms of conduct, polemics against the vices of gambling, fanatism, and pedantry and against the tasteleness of the aesthetes and the eccentricities of the learned. He worked toward the spread of tolerance, the emancipation of civic morality from moral theology and of practical wisdom from the philosophy of teh scholars. The public that read and debated this sort of thing read and debated about itself (1991: 42).

En resumidas cuentas, a lo largo de los más de 300 artículos que Addison publica en esta nueva publicación, el autor se afana en educar a la ciudadanía de su país, empleando para tal fin una prosa rica, elegante y sofisticada pero plenamente democrática ya que el autor era un firme seguidor de los autores clásicos que no concebía separarse lo más mínimo de la máxima horaciana del docere et delectare.

Tras el cierre de The Spectator, Addison funda en el año 1715 un nuevo periódico, que se publicará durante un año y cuya influencia para la culturas y las letras anglosajonas no resulta tan seminal, The Freeholder.

\section{PROBLEMAS TRADUCTOLÓGICOS}

\subsection{ParateXtos latinos}

Como enamorado y buen conocedor de la cultura clásica, Joseph Addison rechaza buscar influencias, ejemplos o acudir al recurso de autoridad en los autores modernos, que considera por lo general inferiores en calidad estética y valor moral con respecto a sus antepasados. De este modo, todos los artículos de opinión, relatos breves y reseñas que publica en The Spectator van precedidas por una breve sentencia o máxima en latín que o bien resume el texto siguiente o bien le sirve al autor como punto de partida para el mismo. De este modo, a lo largo de la vida editorial de The Spectator se incluyen breves textos introductorios de los siguientes autores:

Latinos: Horacio, Marcial, Juvenal, Virgilio, Catulo, Ovidio, Persio, Séneca, Salustio, Publio Siro, Lucano, Cicerón (al que Addison cita como 
"Tully", "Tulio" en español), Terencio, Salustio, Trebonio, Propertio, Tácito, Tribulio, Plinio y Menandro.

Griegos: Homero, Platón, Pitágoras, Hesíodo, Simónides, Teócrito, Stobaeus y Eurípides.

Ni Addison ni Steele ofrecen traducción alguna de estas citas en las versiones originales de sus artículos. No obstante, no cabe duda de que cabía esperar del lector culto del siglo XVIII inglés una familiaridad con las lenguas muertas mucho mayor de la que encontraremos hoy en el lector de los textos traducidos en el contexto socio-cultural de la España actual. Creemos de este modo que, a la hora de enfrentarnos a la traducción y edición de los artículos de Addison en The Spectator, resulta coherente (cuando no abiertamente necesario) ofrecer una traducción al castellano de estas máximas latinas. Sin embargo, la formación de los filólogos y traductores españoles no incluye, por lo general, una reseñable carga lectiva en lo referente a las lenguas muertas de la Antigüedad Clásica.

Cabe señalar que la tarea del traductor y editor se vuelve más ardua incluso, puesto que en el texto original Addison incluye el autor al que pertenece la cita, pero no la obra concreta. Por lo tanto, al traductor español le aguarda una doble tarea de documentación que le permita ubicar la cita dentro del corpus del autor y posterior traducción de la misma.

No obstante, a la hora de acometer esta tarea, también contamos con ayuda, puesto que aunque en The Spectator no se incluyen ni las fuentes de las citas ni sus traducciones, diversas ediciones inglesas que han venido apareciendo desde el siglo XIX de estos artículos sí que las incluyen. Sin embargo, aunque estas ediciones resulten útiles están lejos de resolver el problema por completo puesto que, en demasiadas ocasiones, cometen errores al documentar la procedencia de las citas o (con mayor frecuencia) al traducirlas. Esta situación se agrava en las ediciones que en lugar de ofrecer una traducción directa de la cita latina optan por incluir una paráfrasis en inglés, por lo general obra de algún poeta neoclásica contemporáneo de Addison.

\subsection{PECULIARIDADES LINGÜÍSTICAS}

Desde el siglo XVII en Inglaterra se impone el Early Modern English, antecedente directo y cercano del inglés contemporáneo que ya no ofrece las insalvables dificultades del Old English que se empleó entre los siglos V y XII o del Middle English chauceriano que le sucedió y que, si bien es comprensible requiere de instrucción formal previa, documentación adicional y grandes dosis 
de paciencia. En general, podemos aseverar, aún a riesgo de incurrir en una simplificación excesiva, que desde el Renacimiento inglés, al traductor no les supondrá un esfuerzo excesivo familiarizarse con los textos en esta lengua ni volcarlos a otras lenguas; aunque sin duda el inglés temprano plantea problemas específicos y su traducción se beneficia de la formación en Historia de la Lengua Inglesa y experiencia con textos del período por parte del traductor.

Los textos de Addison presentan ciertas particularidades propias del siglo en el que fueron dados a la imprenta y que son mayores en el caso del inglés del siglo XVIII de sus equivalentes europeos del mismo período. Los motivos por los que el inglés de este momento difiere más de su versión moderna que otros idiomas europeos, así como una de las mayores complejidades para el traductor radica de las numerosas variantes gramaticales y semánticas que aparecían en el inglés, una lengua que estaba lejos de estar consolidada en el momento en que Addison publica estos artículos.

Uno de los principales motivos por los que la lengua de Inglaterra resultaba menos homogénea y contaba con muchas más variantes (regionales y de todo tipo) que sus equivalentes en la Europa continental radica de la inexistencia de una academia de la lengua inglesa. En el momento en el que este texto fueron escritos, en Europa existían ya Academias en Italia (Academia della Crusca, desde 1582); Francia (Académie Française, desde 1635) y Alemania (Deutsche Akademie, fundada en 1700). En España la Real Academia de la Lengua Española entraría en funcionamiento tan sólo dos años después, en 1713, con el célebre lema "limpia, fija y da esplendor", que respondía con exactitud a las necesidades identificadas por Addison en este artículo y el dr. Johnson en su introducción al Dictionary. A diferencia de estos países europeos, donde la creación de academias de la lengua fue, generalmente, loada por los más importantes intelectuales del momento y contó con el apoyo político; en Inglaterra el debate acerca de la necesidad de fundar una institución de esta índole fue enconado y finalmente no fructificó ninguno de los proyectos que pretendían crearla. Así pues, a pesar que ya desde 1570 aparecen volúmenes como The erection of anachademy in London, de Humphrey Gilbert) y que tras la Restauración de 1660 voces tan autorizadas como Abraham Cowley, Daniel DeFoe, John Dryden, el propio Addison, Alexander Pope o Jonathan Swift (que redacta en 1712 su Proposal for Correcting, Improving and Ascertaining the English Tongue) reclamaban la creación de una Academia; el proyecto no resulta fructífero. Lejos de desaparecer con el tiempo, la polémica al respecto de la necesidad de contar con una Academia de la Lengua sigue vivo en el Reino Unido, como prueba el hecho de que la Queen's English Society anunció en junio del año 2010 la creación de la tan ansiada por muchos Academy of the English Language. Sin embargo, las opiniones en la prensa del momento fueron 
principalmente negativas, pocos intelectuales se sumaron al proyecto y la opinión pública general tampoco abrazó el proyecto de forma entusiasta, de modo que en octubre del año 2012 la Queens Society anunciaba que la Academia cesaba sus actividades.

En cualquier caso, aún sin academia del inglés, esta lengua se consolida en gran medida a partir del año 1755 cuando el doctor Samuel Johnson publica A Dictionary of the English Language que, a raíz del gran prestigio del autor y de tratarse de una obra basada en los más apreciados y reconocidos autores ingleses del pasado, se convierte en texto de referencia canónico que pone fin a incontables dudas, disputas lingüísticas y variantes más o menos arbitrarias. Sin embargo, los textos de los que nos ocupamos en el presente artículo vieron la luz entre 1711 y 1712, cuatro décadas antes de la aparición del mencionado diccionario, por lo que no es frecuente encontrar en los mismos términos que resultan arcanos a día de hoy o cuya plasmación escrita difiere de la ortodoxa en mayor o menor medida. Ejemplos de este tipo serían "republick", "tho", "teizing", "propos'd", "chuse" o "publick," entre muchos otros.

\subsection{ASPECTOS HISTÓRICOS Y CULTURALES}

Sin duda, la mayor dificultad que entraña la traducción del corpus periodístico de Joseph Addison viene derivada de los aspectos sociales, culturales y políticos inherentes al mismo. Huelga decir que siempre que nos enfrentamos a un texto que fue escrito hace cuatrocientos años aflorarán este tipo de escollos, puesto que a lo largo de este tiempo la sociedad ha experimentado innumerables cambios, los avances tecnológicos han condenado al olvido más absoluto aquellos utensilios que eran más indispensables en el pasado, las modas a la hora de vestir, adornarse o comer han ido y venido, etc. Consideramos, sin embargo, que el caso del siglo XVIII inglés resulta especialmente problemático por dos motivos principales.

En primer lugar, el lector español estará sin duda familiarizado con el Renacimiento inglés de los Tudor, Sidney, Spencer, Marlowe o Shakespeare o con el siglo XIX de la Revolución Industrial, Marx, Dickens, Jane Austen o las Brönte. Sin embargo, a pesar de su extremada influencia cultural e histórica y del innegable interés que éste ofrece, el período de la Restauración y sus momentos posteriores son menos conocidos para el lector español. En este sentido, grandes literatos del período como Dryden, Pope, o el mismo Addison gozan de mucho menor reconocimiento en España que sus antecesores (como Chaucer, Shakespeare o Milton) o sus sucesores (como los ya mencionados Dickens, Austen, Joyce, etc.). Como resultado, o quizás como responsable de este hecho, las traducciones de los textos del XVIII no abundan en España 
Traduciendo a Joseph Addison: problemas y desafíos

(aunque algunos investigadores como Torralbo Caballero han venido, en gran medida, a paliar esta situación en los últimos años)

En segundo lugar, el momento en el que Addison da a la imprenta los textos que nos ocupan, Inglaterra vive uno de los momentos más convulsos y tensos de su historia, desde un punto de vista político, existe una incesante polémica entre los dos principales bandos políticos del momento (whigs y tories), las colonias americanas han comenzado ya a transitar lentamente el camino hacia su independencia que culminará en las últimas décadas del siglo XVIII, las relaciones de Inglaterra con otras coronas europeas son, cuando menos, complejas, etc. Tampoco proliferan en las librerías o bibliotecas de nuestro país libros de historia sobre este período histórico concreto, por lo que los textos de Addison están plagados de referencias, guiños y menciones a eventos que sus coetáneos no tendrían problema alguno en identificar pero que, sin embargo, para el lector español son oscuros en el mejor de los casos e indescifrables en muchos otros.

A continuación ofrecemos diversos ejemplos paradigmáticos de este tipo de dificultades de tipo socio-histórico o cultural, tomando como ejemplo el artículo que The Spectator publica el 8 de marzo de 1711, en el autor se afana en probar como insensatas la superstición y creencias generalizadas en las apariciones espectrales, hechos sobrenaturales o tabúes relativos a la mala suerte.

Para entender el texto en general y muchas de sus referencias concretas, se hace imprescindible tener en cuenta que, a pesar de que el siglo XVIII en Inglaterra corresponde con un período de expansión cultural y avances científicos que nos permiten referirnos a este momento histórico como el verdadero siglo de la razón, las creencias en fantasmas, espíritus y otros fenómenos paranormales estaban muy extendidas, tanto entre la alta sociedad metropolitana como entre los sectores más populares de la ciudad y el territorio rural del país.

En este sentido, resulta importante mencionar que el clima de superstición imperante en el Reino Unido durante el momento en que Joseph Addison compone el presente ensayo es tal que incluso desde una perspectiva legal se sigue persiguiendo la brujería. De hecho, en Inglaterra la última condena a muerte en un proceso de persecución de brujería acontece en el año 1712, tan sólo un año después de la publicación de este texto, cuando Jane Wenham, vecina de Walkerne, es sentenciada a muerte tras considerarse probadas sus males artes y comercio con el Maligno. Debemos asimismo reseñar que el propio Addison se hace eco del comienzo de dicho proceso judicial en otro artículo publicado en The Spectator número 117, correspondiente al día 14 de julio de 1711.

De este modo, aunque es cierto que el gran interés por la exploración 
paranormal que se dará en Londres durante el siglo siguiente (y que convertirá las sesiones de espiritismo en ubicuas entre las reuniones sociales de la clase alta británica y hará que, entre otros prominentes intelectuales del momento, Charles Dickens y Arthur Conan Doyle se conviertan en firmes creyentes); expertos como Sasha Handley defienden que la mayor parte de supersticiones contemporáneas se consolidan precisamente durante el siglo XVIII, momento en el que también se gesta el género literario fantasmal en forma de relatos breves terroríficos. Los lectores interesados en estas cuestiones encontrarán interesantes los trabajos de la mencionada Handley (Visions of an Unseen World: Ghost Beliefs and Ghost Stories in Eighteenth Century England, 2007) y True Irish Ghost Stories (selección de relatos de fantasmas elaborada en los albores del siglo XX por el sacerdote John D. Seymour; que incluye como primeros ejemplos las seminales historias breves de fantasmas producidas durante el siglo XVIII a las que venimos refiriendo.

Por último, es importante mencionar que otra ilustre figura de las letras inglesas del siglo XVIII, el dr. Samuel Johnson, también se interesó por restar credibilidad a los numerosos relatos de fantasmas y casas encantadas que circulaban por Londres, como se lee en The Life of Samuel Johnson, de James Boswell (357: 1824). Nos permitimos aquí reproducir una célebre máxima de Johnson en la que resume esta cuestión: "Resulta maravilloso que hayan pasado cinco mil años desde la creación del mundo y todavía no quede claro si se ha producido o no un sólo caso del espíritu de una persona que se aparezca tras su muerte. Todos los argumentos están en contra de esta posibilidad, aunque todas las creencias estén a favor" (252: 1824).

En este mismo texto encontramos la siguiente frase: "Thursday, says she, no, Child, if it please God, you shall not begin upon Childermas-day; tell your Writing-Master that Friday will be soon enough," cuya traducción sería "No, mi hijo. No debes, para complacer a Dios, hacerlo en el día de los Inocentes. Dile a tu maestro que el viernes será, como muy pronto.” Aunque la referencia al Día de los Inocentes sería en España entendible, hay que tener en cuenta determinadas peculiaridades, en este caso particular; puesto que en Inglaterra, como en España, el día 28 de diciembre se conmemora el día de los Inocentes (conocido como Holy Innocents' Day o Childermas), que rememora las matanzas ordenadas por Herodes en Bethlehem. Tradicionalmente, en Inglaterra, se evitaba cuidadosamente iniciar nuevos proyectos o contraer matrimonio en esta fecha. La conmemoración resultaba especialmente ominosa en caso de coincidir el día 28 de diciembre con el día de domingo, en cuyo caso se solía considerar que durante el día 28 de cada mes debían evitarse los matrimonios o dar comienzo a proyectos de envergadura. Aunque existen numerosas anécdotas históricas relacionadas con esta celebración, la más relevante tiene que ver con la coronación del rey Eduardo IV, que estaba 
Traduciendo a Joseph Addison: problemas y desafíos

inicialmente prevista para el día 28 de junio del año 1461 pero pospuesta hasta el lunes siguiente una vez que el monarca fue informado de que el año anterior, el Día de los Inocentes había ocurrido en domingo.

Además de esta referencia al Día de los Inocentes, en el mismo texto aparece otra de tipo histórico que merece ser mencionada: "Yes, says he, my Dear, and the next Post brought us an Account of the Battel of Almanza." Aunque la batalla de Almansa se libra en España, ésta resultará mucho más importante y es mejor recordada en Inglaterra; por lo que creemos conveniente ofrecer al lector español en nota al pie la siguiente información: La Batalla de Almanza, que se libró el 25 de abril del año 1707 en la provincia de Albacete, supuso uno de los más importantes choques bélicos en la Guerra de Sucesión española (1701-1714); conflicto originado por la sucesión de Carlos II en España que muy pronto alcanzó proporciones internacionales. En esta batalla concreta, las tropas franco-españolas (que apoyaban a los Borbones) y estaban lideradas por James FitzJames, Primer Duque de Berwick, infligen una sonada derrota a la coalición de fuerzas formada por Portugal, Bretaña y las Provincias Unidas (actual Holanda), que apoyaban a los Austracistas y eran comandadas por Henri de Massue, Conde de Galway. La derrota en Almansa supuso un duro golpe para los ingleses, que recordarán durante siglos, como demuestra el hecho de que Winston Churchill en una comparecencia ante la Cámara de los Comunes el día 2 de mayo de 1935 recordara esta batalla, comparándola con el terrible daño que las tropas nazis estaban causando al ejército británico.

Como curiosidad histórica, resulta interesante señalar tanto que Federico II de Prusia consideró esta batalla como "la más científica de nuestro siglo" como el hecho de que es el único conflicto en la historia en que un militar inglés comanda a las tropas francesas y uno francés a las inglesas cuando éstas combaten entre sí.

Tras solventar este problema derivado del contexto histórico, muy pronto nos topamos en este mismo artículo con otro, de carácter mucho más banal, cuando leemos en el original: "I have known the shooting of a Stars poil a Night's Rest; and have seen a Man in Love grow pale and lose his Appetite, upon the plucking of a Merry-thought". La referencia al "Merry-thought" resulta absolutamente indescifrable si no investigamos respecto a una superstición inglesa completamente perdida a día de hoy. Esta ancestral superstición consistía en que, como instancia previa al matrimonio, la novia y una de sus amigas tiraban de una fúrcula de pollo (pequeño hueso en forma de $y$ que sólo poseen las aves, donde se unen sus dos clavículas). Si la futura esposa conseguía la parte más alargada del hueso, el matrimonio resultaría fructífero; pero en caso contrario estaba destinado al fracaso. El Imperio Romano toma esta ceremonia de los Etruscos y la introduce entre los Bretones 
y ya en 1589 tenemos testimonios escritos de esta práctica (conocida como Merry-thought) en suelo inglés; aunque ésta llevaba siglos llevándose a cabo.

Una vez desentrañados los secretos del hueso de pollo profético, el traductor se enfrenta a un nuevo problema en el siguiente párrafo, donde Addison afirma lo siguiente: "An old Maid, that is troubled with theVapours, produces infinite Disturbances of this kind among her Friends and Neighbours". Esta breve frase nos obliga de nuevo a llevar a cabo una investigación que, en este caso, nos conduce a textos médicos ingleses antiquísimos y prácticamente olvidados a día de hoy; pero sin los cuales la referencia a "vapours" resulta, cuando menos, ambigua. En el año 1707 el médico inglés John Purcell publica el libro A treatise of vapours, or bysterick fits. Containing an analytical proof of its causes, mecanical explanations of all its symptoms and accidents, according to the newest and most rational principles. Together with its cure at large. En esta obra, Purcell intenta encontrar explicación científica a determinadas afecciones mentales, ya que se niega a aceptar que los pacientes mentales sean simplemente "locos" o se encuentren poseídos por espíritus preternaturales. En esta obra, Purcell se centra en particular en dos enfermedades que él considera vinculadas y a las que refiere como Fits of the Mother (la epilepsia y la histeria). De manera muy somera, la teoría de Purcell explica que tanto la histeria como la epilepsia se originan cuando los vapores de la matriz ascienden a la cabeza, provocando trastornos emocionales. De ahí el nombre que da a las afecciones y el hecho de que las considerara como propias de la mujer. Aunque sin duda Purcell está muy lejos de encontrar la raíz de estas enfermedades y de comprenderlas y no se separa en demasía de la teoría medieval de los humores; debe reconocerse la labor que el investigador llevó a cabo a la hora de estudiar las enfermedades mentales como propias de la medicina, dotando por lo tanto de dignidad a unos pacientes que tradicionalmente habían sido condenados al más terrible ostracismo social y degradación. Por otra parte, aunque no comprendiera las causas de la epilepsia, alguno de los consejos que da para su tratamiento (así como para la correcta certificación de la muerte de una paciente epiléptica) apuntaban en la dirección correcta.

En lo que respecta a Addison, el hecho de que en 1711 se hiciera eco de las teorías de Purcell demuestra una vez más su curiosidad por todas las ramas de la ciencia y voracidad lectora, ya que aunque la teoría de los vapores se hará muy popular posteriormente en Inglaterra, tan sólo 4 años después de la publicación del libro pocos eran los que fuera de los círculos médicos estaban familiarizados con este trabajo. 


\section{CONCLUSIONES}

Joseph Addison es una de las figuras claves dentro de las letras inglesas del siglo XVIII y los numerosos artículos que publicó en The Tatler, The Spectator y, en mucha menor medida, en The Freeholder no sólo contribuyeron a la consolidación de la sociedad de la época sino que han entrado a formar parte de la cultura inglesa y siguen a día de hoy leyéndose y siendo estudiados. Sin embargo, no es un autor que haya recibido especial atención por parte de los críticos españoles y tampoco abundan las traducciones de Addison al español. De hecho, en las dos últimas décadas no han aparecido sino una traducción de ensayos selectos de Addison, Los placeres de la imaginación y otros ensayos (en el año 1991, a cargo de Tonia Raquejo); así como un artículo breve del autor que apareció traducido en el año 2006 en el volumen de Paula Martín Salván, El espiritu del lugar: Espiritu y paisaje en la Inglaterra moderna. En el presente artículo hemos examinado en profundidad las complejidades que entraña la tarea de volcar al español los elegantes y delicados textos del autor, tomando como ejemplo un artículo paradigmático que el mismo dio a la imprenta en 1711.

Este trabajo no pretende sino servir de punto de partida a un análisis más amplio, que de manera complementaria a la traducción de una colección de textos del autor nos encontramos en este momento culminando y que, esperamos, sirva para paliar en alguna medida la ausencia de traducciones de calidad de textos del autor que en el presente momento experimentamos en España.

\section{BIBLIOGRAFÍA}

Addison, Joseph (1970). The Spectator: Essays. Londres, Printed for members of the Limited Editions Club at the Curwen Press.

(1970). Cato: a Tragedy. Indianapolis, Libert Fund.

---- (1970). Addison and Steele: Selections from the Tatler and the Spectator. Nueva York, Holt.

Aikin, Lucy (1843). The Life of Joseph Addison. Londres, Longman, Brown, Green and Longmans.

Boswell, James (1791). The Life of Samuel Johnson. Londres, H. Baldwin for C. Dilly.

Gilbert, Humphrey (1869). The erection of an achademy in London for educacion of her Maiestes wardes, and others the youth of nobility and gentlemen. Londres, Early English Text Society.

Graham, James (1941). The Letters of Joseph Addison. Oxford, The Clarendon Press. 
Habermas, Jürgen (1991). The Structural Transformation of the Public Sphere: an Inquiry into a Catergory of Bourgeois Society. Boston, MIT Press.

Handley, Sasha (2007). Visions of an Unseen World: Ghost Beliefs and Ghost Stories in Eighteenth Century England. Nueva York, Pickering \& Chatto.

Johnson, Samuel (1768). A Dictionary of the English Language. Dublín, W. G. Jones.

Knight, Charles (1994). Joseph Addison and Richard Steele: a reference guide, 1730-1991. Nueva York, G. K. Hall.

Lannering, Jan (1977). Studies in the Prose Style of Joseph Addison. Philadelphia, R. West.

Lubey, Kathleen (2012). Excitable Imaginations: Eroticism and Reading in Britain, 1660-1760. Lewisburg, Bucknell University Press.

Martín, Paula (2007). El espiritu del lugar: Espiritu y paisaje en la Inglaterra moderna. Madrid, Abada.

Maurocordarto, Alexander (1964). La critique classique en Angleterre, de la Restauration à la mort de Joseph Addison; essai de définition. París, Etudes anglaises.

Otten, Robert (1982). Joseph Addison. Boston, Twayne.

Purcell, John (1707). A treatise of vapours, or bysterick fits. Containing an analytical proof of its causes, mecanical explanations of all its symptoms and accidents, according to the newest and most rational principles. Together with its cure at large. Londres, Printed for Edward Place.

Seymour, John (1914). True Irish Ghost Stories. Dublín, Hodges, Figgis \& Co.

Smithers, Peter (1968). The Life of Joseph Addison. Oxford, London, Clarendon Press.

Swift, Jonathan (1712). Proposal for Correcting, Improving and Ascertaining the English Tongue. Londres, Benj. Tooke.

Torralbo, Juan (2007). Ensayos sobre la literatura de los siglos de oro. De Cervantes a Pope. Granada, Grupo Editorial Universitario. 